\title{
Gol y memoria: el fútbol en la narrativa en lengua española del XXI
}

\author{
Goal and Memory: Soccer on Narrative in Spanish of the 21st Century \\ David García Cames \\ Universidad de Salamanca - Salamanca, Espanha
}

$\diamond$

\begin{abstract}
Resumen: El fútbol es un relato que el aficionado busca fijar en la memoria. La literatura aporta al balompié la creación de un universo simbólico que persigue trascender los acontecimientos de la cancha. Este artículo plantea una panorámica a través de la narrativa del fútbol en lengua española del siglo XXI, poniendo de relieve sus principales dinámicas, autores y obras. El cuento y la novela conviven durante estos años con formas híbridas a medio camino del ensayo y la ficción. Escritores a uno y otro lado del Atlántico consolidan el tratamiento literario del fútbol como motivo de indagación estética y sentimental. El gol, para muchos de ellos, puede ser epifanía, pasión y metáfora.
\end{abstract}

Palabras clave: Fútbol y literatura; Narrativa en español; Memoria sentimental

\begin{abstract}
Soccer is an account that the supporter needs to keep in his memory. Literature provides the football with the creation of a symbolic universe that transcends the events of the field. This paper presents an overview through the soccer narrative in Spanish of 21st century, highlighting its main dynamics, authors and works. Short story and novel coexist during these years with hybrid forms between the essay and fiction. Writers on both sides of the Atlantic consolidate the literary treatment of soccer as a source of aesthetic and sentimental inquiry. The goal, for most of them, can be epiphany, passion and metaphor.
\end{abstract}

Keywords: Soccer and Literature; Narrative in Spanish; Sentimental Memory

\section{Introducción}

Un defensa debe dejar que pase la pelota o pase el jugador, pero no los dos. La literatura es igual: a veces pasa la historia, pero no el autor.

(JUAN VILLORO: "Yo soy Fontanarrosa")

El fútbol, en contra de las apariencias, necesita de la palabra para persistir. El gol, sin el grito que consagra su instante, está condenado a agotarse en la fugaz memoria del aficionado. El fútbol se expresa de este modo a través de un relato incesante que aspira a demorarse más allá del rectángulo de juego: "Y es que el fútbol es, en sí mismo, asunto de la palabra. Pocas actividades dependen tanto de lo que ya se sabe como el arte de reiterar las hazañas de la cancha" (VILLORO, 2006, p. 22). El hincha precisa contar una y otra vez aquel regate prodigioso del delantero centro que acabó con el defensa tirado en el suelo, aquel tanto milagroso que culminó una remontada épica en el último minuto del descuento. Este carácter narrativo del propio acontecimiento futbolístico ha planteado dificultades a muchos escritores que, en el intento de trasladar a la ficción el deporte más popular del planeta, se han sentido abocados a caer en el riesgo de una cierta redundancia. Frente a esta postura, la denominada literatura del fútbol ha pretendido ir más allá, descubrir en el balompié una puerta de entrada a un universo simbólico conformado por aquellos personajes y hechos que lo protagonizan. Cuando no se limita a una estéril reproducción, cuando suprime la redundancia en el empleo certero de la metáfora, la narrativa del fútbol es capaz de alumbrar una creación lingüística donde se concitan el símbolo y la palabra poética. De esta forma, las obras que tematizan el fútbol serán tanto más reseñables cuanto más se acerquen a aquellos motivos íntimos y elementos míticos que hacen 
de este deporte un fenómeno global de proporciones inabarcables. El fútbol es pasión, delirio, violencia, dicha, éxtasis y juego pero, sin lugar a dudas, el fútbol es también un relato proteico e inagotable: "El fútbol es para contar. No es un deporte, contra las evidencias, sino un relato. Jugarlo a secas como si fuese un altercado de once tipos contra once tipos [...] resulta del todo vulgar y efímero. La belleza se escribe" (TALLÓN, 2014, p. 123).

Desde el primer cuento semificcional sobre fútbol publicado por Horacio Quiroga en 1918 (“Juan Polti, half-back"), pasando por las novelas pioneras de los españoles José Antonio de Zunzunegui (Chiripi. Historia bufo-sentimental de un jugador de foot-ball, 1931) o Wenceslao Fernández Flórez (El sistema Pelegrín, 1949); la narrativa en lengua española ha ido abriendo un espacio cada vez mayor a este deporte. Autores como Mario Benedetti ("Puntero izquierdo", 1955), Camilo José Cela (Once cuentos de fútbol, 1963) o Gonzalo Suárez (Los once y uno, 1964) entregarán algunos de los textos más reseñables en esta evolución. A principios de los setenta, una serie de autores, principalmente en el entorno del Río de la Plata, comenzarán a reivindicar una legitimación del fútbol dentro de la literatura y de la considerada alta cultura. En esta tendencia podríamos situar a los argentinos Osvaldo Soriano y Roberto Fontanarrosa, considerados los principales referentes de la narrativa del fútbol gracias a cuentos clásicos como "19 de diciembre de 1971" o "El penal más largo del mundo". Si bien Fontanarrosa continuaría publicando hasta su muerte, ocurrida en 2007, el grueso de su producción se concentra en las últimas décadas del XX, hecho que nos lleva a dejarlo fuera del recuento llevado a cabo en este trabajo. En España, todos estos autores hallarían eco en las obras de escritores como Antonio Hernández (El Betis: la marcha verde, 1978) o Manuel Vázquez Montalbán (El delantero centro fue asesinado al atardecer, 1988). Muchos de ellos serían admirados y encontrarían continuidad en autores tan diversos como Antonio Skármeta (Soñé que la nieve ardia, 1975), Manuel Longares (No puedo vivir sin ti, 1995), Eduardo Galeano (El fútbol a sol y sombra, 1995), Pedro Ángel Palou (El último campeonato mundial, 1997) o Javier Marías (Salvajes y sentimentales, 2000).

Dentro de la popularización de la narrativa del fútbol también desempeñarán un papel destacado las antologías de cuentos como las que, en 1995 y 1998, editará en España el ex futbolista argentino Jorge Valdano. Este hecho hallará reflejo en América Latina, principalmente en Argentina, de la mano de antologías al cuidado de Fontanarrosa (Cuentos de fútbol argentino, 1997) o el locutor radiofónico Alejandro Apo ( $Y$ el fútbol contó un cuento, 2007) ${ }^{1}$. De esta forma, el fútbol se consolida paulatinamente como tema literario en la narrativa española y latinoamericana, alcanzando un notable desarrollo a finales de los noventa y comienzos del XXI. Apunta al respecto la crítica venezolana Yvette Sánchez (2010) que durante estos años se produce "un cambio paradigmático del estatus del fútbol: se ha emancipado de los prejuicios, se ha legitimado, incluso ennoblecido y, por ende, tanto escritores como lectores confiesan su querencia por este deporte". El balompié se torna un tema recurrente dentro de la literatura en castellano en la medida en que permite acercarse y explorar la cartografía emocional del ídolo y del hincha. La literatura resignifica así el fútbol, lo convierte en metáfora sobre la que plantear algunas preguntas esenciales del ser humano. Como ha señalado al respecto Fernando Aínsa (2003, p. 115), las manifestaciones deportivas, cuyos escenarios y héroes encarnan auténticas alegorías, se incorporan a la literatura como una "temática que aspira a reflejar la compleja realidad socio-cultural contemporánea a través de una visión más antropológica que política o meramente estética".

\section{Memoria sentimental y futbolera}

Una vez legitimado, una vez descubierto su espacio en la literatura de ficción, el fútbol persigue fijarse en la palabra como tema literario y símbolo memorable. Al amparo de las corrientes estéticas y de pensamiento que llevan a las sociedades occidentales a consagrar durante la primera década del siglo XXI un "culto a la memoria" (SÁNCHEZ ZAPATERO, 2010, p.25), la narrativa del fútbol también echará la vista atrás para encontrar allí algunos de sus principales motivos. La nostalgia, la reivindicación del fútbol como imagen de la infancia, como recuerdo cargado de significado, se volverá una constante en muchos de los libros que se publican durante estos años. Frente a las mezquindades del fútbol profesional reflejadas en la novela

\footnotetext{
En este artículo no nos detendremos en las numerosas antologías de relatos futbolísticos en castellano que han visto la luz en los últimos años, algo que merecería un estudio detallado. Dejamos aquí una pequeña muestra con algunos de los títulos más destacados de las dos primeras décadas de este siglo, especificando, de haberlo, el nombre del editor y el país de publicación: Área de candela. Fútbol y literatura (Raúl Pérez Torres, Ecuador, 2006); De puntín: los mejores narradores de la nueva generación escriben sobre fútbol (Diego Grillo Trubba Argentina, 2008); Cuentos mundialistas (Carlos Barrón, México, 2010); La garra catracha. Literatura y fútbol (Helen Humaña, Honduras, 2010); El fútbol se lee (Luis Alejandro Díaz Zuluaga, Colombia, 2011); Bien jugado. Las patadas de una ilusión. Letras y pasión en el fútbol peruano (Jorge Eslava, Perú, 2011); Punta Karaja. Cuentos de fútbol (Paraguay, 2012); Todo es cancha. Antología de cuentos de fútbol (Chile, 2014); El derbi final (España, 2016) y, por último, mencionamos un libro de relatos escrito por futbolistas y entrenadores: Pelota de papel (Sebastián Domínguez y Agustín Lucas, Argentina, 2016).
} 
negra $^{2}$, la narrativa balompédica propondrá una reivindicación de los lugares en los que el juego aparece aún libre, incontaminado. Los escritores tratarán de compensar "la imagen de lujo y mercantilización presente en los estadios de hoy", deleitándose en la infancia ya remota "con recuerdos de una infraestructura más que modesta e insuficiencias materiales" (SÁNCHEZ, 2007, p. 135). Campos de tierra, balones desvencijados o camisetas deshilachadas se convierten, de esta forma, en metáforas recurrentes de las obras de este periodo, muchas de las cuales se entregarán a la evocación nostálgica de un fútbol ya desaparecido. El balompié se renueva en la palabra y a través de la palabra busca acercarse a la esencia de su componente lúdico. Tal y como afirmaba Huizinga (2008, p. 23), el juego "permanece en el recuerdo como creación o como tesoro espiritual, es transmitido por tradición y puede ser repetido en cualquier momento".

Así como en la literatura hispanoamericana se produce una reactualización de la memoria colectiva con la voluntad de conceder voz a los olvidados por la historia, así la literatura del fútbol, en tanto expresión de la cultura popular, irá configurando una auténtica memoria sentimental ligada a viejos ídolos, patios de escuela o partidillos bajo la lluvia. El fútbol se presenta entonces como un salvoconducto gracias al cual tanto el autor como el lector acceden a lugares intransferibles del pasado, símbolo que remite a ciertas experiencias básicas y comunes: "Vemos partidos y escribimos de fútbol para recuperar la infancia, no la que en verdad vivimos, sino la que nos asignamos a nosotros mismos" (VILLORO, 2014, p. 20). Los escritores encuentran en el fútbol un motivo de indagación personal, una imagen de matriz prácticamente proustiana que descubre en el juego un punto de conexión con experiencias fundacionales que es preciso plasmar en la palabra: "El fútbol se muestra de esta manera como vehículo de transmisión preferente, donde la tradición aparece con toda su carga de divinidad, de cosa sacra" (NACACH, 2006, p. 28). Todo esto se traducirá también, junto a la consolidación del fútbol como tema literario en el cuento y la novela, en el desarrollo de formas híbridas a medio camino del ensayo y la ficción, como podrían ser el relato de forofos o los dietarios futbolísticos, dando lugar en su conjunto a una renovación y afianzamiento del tema.

Uno de los escritores que mejor encarnará esta memoria sentimental y futbolera será el argentino

\footnotetext{
2 Para ampliar información sobre el fútbol en la ficción criminal española y latinoamericana puede consultarse el artículo: GARCÍA CAMES, David: Nadie escuchó los llantos: fútbol, crónica y represión en la novela negra hispánica del XXI. Pasavento: revista de estudios hispánicos, v. 4, n. 1, p. 39-62, 2016. Disponible en: <http://dspace.uah.es/dspace/ handle/10017/24484>. Acceso en 2 feb. 2017.
}

Eduardo Sacheri. Considerado por muchos como el principal heredero de la tradición de la narrativa balompédica argentina, el autor nacido en Castelar defenderá a lo largo de su producción la idea del fútbol en tanto vehículo que permite expresar vivencias fundamentales, según sostiene en el prólogo de su antología La vida que pensamos: "El fútbol, como parte de esa vida que tenemos, me sirve entonces como una puerta de entrada a esos mundos íntimos en los que se juegan asuntos mucho más definitivos" (SACHERI, 2014, p. 10). Autor de libros de cuentos, novelas y artículos en los que el fútbol desempeña un papel destacado, Eduardo Sacheri saltó a la fama gracias al programa radiofónico "Todo con afecto", del periodista Alejandro Apo, donde la lectura de sus cuentos obtuvo una gran acogida por parte de los oyentes. Relatos como "Me van a tener que disculpar", "Esperándolo a Tito" o "De chilena" popularizaron la figura de un profesor de historia sin ninguna experiencia en el mundo editorial que parecía conectar a la perfección con el imaginario futbolístico de los argentinos.

Al poco tiempo verían la luz sus primeros libros de relatos: Esperándolo a Tito (2000); Te conozco, Mendizábal (2001); Lo raro empezó después (2004), y Un viejo que se pone de pie (2007). Más tarde publicaría un libro de narraciones destinado al público juvenil (Los dueños del mundo, 2012), además de una recopilación con algunos de sus mejores cuentos sobre fútbol ( $\mathrm{La}$ vida que pensamos, 2013). Tras el éxito de sus libros de relatos, Sacheri publicará La pregunta de sus ojos (2005), novela llevada al cine cuatro años después como $E l$ secreto de sus ojos, dirigida por Juan José Campanella y ganadora del Oscar en 2010. Frente a lo que ocurre en la película, el fútbol tendrá una escasa presencia en el libro, algo que se repite en la mayoría de sus novelas: Aráoz y la verdad (2008), Ser feliz era esto (2014) y La noche de la Usina (2016), ganadora del Premio Alfaguara. La novela de Sacheri en la que el fútbol se situará en el eje de la trama será Papeles en el viento (2011), también llevada al cine en 2015 y donde narra la historia de un grupo de amigos que se hace con los derechos de un jugador. Devoto de Club Atlético Independiente de Avellaneda hasta sus últimas consecuencias, capaz de asistir a la ceremonia de los Oscar pendiente de los resultados de su equipo, Eduardo Sacheri será el narrador del amor filial que crece al amparo del fútbol, de los partidos que se alargan hasta llegar la noche en los potreros, de las promesas y las pasiones innegociables, del vínculo sentimental que se forja en el imprevisible bote de una esfera.

Además de la revitalización del tratamiento literario del fútbol en la narrativa breve argentina gracias a los relatos de Sacheri y a los libros publicados por la editorial 
Al $\mathrm{Arco}^{3}$, nos encontramos a partir del año 2000 con otros destacados cuentos sobre fútbol en la literatura latinoamericana. Sin lugar a dudas, uno de los más relevantes será el relato "Buba", incluido por Roberto Bolaño en Putas asesinas (2001) y en el que narra el ascenso y caída de un jugador africano después de fichar por un equipo de Barcelona. Entre evocaciones de magia negra y elementos de tragedia griega, Bolaño demuestra su afición por el fútbol a la vez que juega narrativamente con algunos de sus mitos y ritos. Como afirma Yvette Sánchez (2010), "el cuento está escrito sin aparentes alardes, tan hábilmente camuflada la narración bajo una escritura común y corriente simulando un carácter documental”. El también chileno Reinaldo Edmundo Marchant ahondará en el tema convirtiéndose en el autor más prolífico de relatos sobre fútbol del país con sus libros La alegría del pueblo (2004), Toco y me voy (2006), Fintas y gambetas (2006) y El ángel de las piernas torcidas (2009). La nostalgia estará muy presente en unos cuentos que rinden tributo a las emociones desatadas del fútbol y a ídolos de antaño como el brasileño Garrincha. Por lo que se refiere a otros autores argentinos que publican libros de relatos sobre fútbol en esta época podemos destacar a Juan Sasturain (Wing de metegol, 2004, y Picado grueso, 2006); Rafael Bielsa (Fuga y misterio. Cuentos de amor y fútbol, 2008); Rodolfo Braceli (Perfume de gol, 2009, y Querido enemigo, 2013), y Ariel Magnus (Ganar es de perdedores, 2010). En todos ellos, desde diferentes enfoques, observamos la presencia del fútbol como elemento recurrente de la memoria de hinchas y aficionados. Por último, mencionamos el libro de cuentos del cubano Ariel Lunar Cábalas y amuletos (2011), ópera prima de este escritor que permite contemplar "el impacto que tiene el fútbol en un país donde no hay tradición futbolera importante" (DÍAZ ZULUAGA, 2014, p. 323).

En la ficción breve española, uno de los escritores que mejor sabrá abordar el fútbol por estos años será el jerezano Juan Bonilla. Si bien no cuenta con un libro, ya sea de poesía o prosa, dedicado en exclusiva al fútbol, su afición se dejará sentir tanto en su obra poética como narrativa. Bonilla, tras incluir el relato "A veces es peligroso marcar un número de teléfono" (1998) en la segunda antología de Valdano, nos dejará otros cuentos en los que el fútbol resulta determinante: "El estadio de mármol" y "Encuentro en Berlín" (El estadio de

\footnotetext{
3 Esta editorial argentina especializada en literatura deportiva publicará libros de cuentos sobre fútbol de los siguientes autores: Walter Vargas (Del diario intimo de un chico rubio, 2004); Ariel Scher (Wing izquierdo, el enamorado, 2005, y Fútbol en el bar de los sábados, 2008); Gustavo Grabia (Disquisiciones sobre la habilidad, 2004, y El club del fin del mundo, 2005); Marcos González Cezer (Pies negros, 2005); Gustavo Yarroch (Jueguen por abajo, 2006); Julio Boccalatte (El jardín de los ekekos, 2009); Cristian Garófalo (El arquero nada pudo hacer, 2010), y Pablo Sehtman (Huele a tablón, 2010).
}

mármol, 2005); "El cromo de Boronat" (Tanta gente sola, 2009), y "El sol de Andalucía embotellado" (Una manada de ñus, 2013). Al modo de los autores argentinos, Juan Bonilla proclamará en diversos artículos la pasión por los colores de sus dos equipos, el Barça y el Xerez, mientras exalta el papel de fútbol como símbolo originario anclado en la infancia: "Las primeras ficciones, en fin, que me atreví a imaginar eran partidos de fútbol disputados con cromos y que me enseñaron a mejorar la realidad, pues allí donde ésta hacía acumular derrotas a mi equipo favorito, yo la corregía" (BONILLA, 2008, p. 133-134).

Otros destacados autores españoles consagrarán relatos breves al mundo del fútbol en la primera década del XXI. Entre ellos podríamos nombrar a Almudena Grandes con el cuento "Demostración de la existencia de Dios" (Estaciones de paso, 2005); Manuel Rivas con "El partido de Reyes" (Cuentos de un invierno, 2005); Mario Cuenca Sandoval con "Los mártires del balompié", relato sobre un futbolista hindú que se alzó con el Premio Píndaro convocado en 2008 por el Ministerio de Cultura venezolano; y Juan Carlos Márquez con "Belgrado 1976" (Llenad la Tierra, 2010), cuento que recrea los días previos al famoso penalti lanzado por el checo Antonín Panenka en la final de la Eurocopa. También hallamos referencias al fútbol jugado en la infancia en el libro de relatos La mesa puesta (2010), de Manuel Abacá. Ya en 2012, Ana María Moix reuniría algunos cuentos balompédicos en Un poco de pasión y otros cuentos de fútbol. El tratamiento del fútbol en la narrativa breve española responderá a las mismas premisas que ya hemos visto en los autores latinoamericanos. Hablamos de relatos que, por citar algunas de sus líneas argumentales, emplean la potencialidad del fútbol como forma de acceder a episodios decisivos de la adolescencia, que desde la ironía reformulan la imagen tradicional del héroe o que bien tratan de encontrar alguna explicación a la pasión desmedida de un hincha. Además de estas obras de ficción, muchos de los autores españoles que acabamos de mencionar también escribirán sobre fútbol en la prensa; autores a los que durante estos años habría que sumar otras plumas que seguirán plasmando su afición futbolera en los medios de comunicación, como Ray Loriga, Javier García Sánchez, Javier Marías o Enrique Vila-Matas.

En la tematización del fútbol dentro de la novelística española a partir del año 2000 se observa una insistencia en los motivos que venimos detallando. En 2002 se publican dos novelas que tienen como ejes principales el fútbol y África. Miguel Bayón, en Mulanga, narra con tintes de humor surrealista la historia de un entrenador de segunda división que acaba dirigiendo a una selección africana. Por su parte, Jorge Botella, en Cláusula de rescisión, construirá una novela en torno a las cartas que un jugador africano envía desde España. El tema haría 
fortuna por aquellos años, puesto que otras novelas como El factor Rh (Carlos Eugenio López, 2003) y Tez color de aceituna (Jesús Enrique Martínez, 2004) incidirán también, desde diferentes puntos de vista, en personajes llegados de África que deben afrontar grandes dificultades para integrarse en la cultura europea. En 2008 aparece uno de los libros esenciales de cara a la consolidación del tratamiento literario del fútbol en la novela española: Saber perder, del escritor y cineasta madrileño David Trueba. Libro coral donde se entrecruzan los destinos de cuatro personajes, la trama más desarrollada estará protagonizada por un futbolista argentino durante su primer año en la Liga española. Trueba, amigo de Pep Guardiola $^{4}$, demostrará su profundo conocimiento del juego y de las dinámicas que rodean al fútbol profesional con la intención, tal y como confesaba en una entrevista, de ir más allá de la visión demasiado tópica que tiene el público de los jugadores, "como si estos chicos no fueran personas normales de 20 ó 22 años" (RODRÍGUEZ, 2015, p.93).

El onubense Coradino Vega retrataría las relaciones de un adolescente con su padre, ex futbolista y entrenador, en El hijo del futbolista (2010). Ambientada en un entorno rural, nos hallamos frente a una novela de iniciación donde se combina la reivindicación de la memoria colectiva ligada a la explotación de las minas de Riotinto por parte de los ingleses, con la memoria sentimental encarnada en viejos campos de fútbol. En 2010 también se publican las novelas La bufanda, donde el asturiano David Artime Coto dibuja las andanzas de un ultra del Sporting de Gijón, y Regreso a Vadinia, relato de tintes autobiográficos del ex futbolista Manuel Vicente González. En 2012, por su parte, Fernando Fedriani publica Menta y nata, presentada como la primera novela histórica del Real Betis Balompié. La novela más relevante publicada en España durante este periodo en cuanto al tratamiento literario del fútbol será Aquella edad inolvidable (2012), del escritor vasco Ramiro Pinilla. En ella se aborda la caída en desgracia de un futbolista del Athletic de Bilbao que, tras haber alcanzado la gloria después de derrotar al Real Madrid con un gol suyo en la final de la Copa del Rey, queda cojo a causa de una terrible lesión. El contraste entre las clases bajas y la burguesía vasca durante los años cuarenta, la súbita decadencia del ídolo o el simbolismo de los cromos

\footnotetext{
4 David Trueba entregaría un completo retrato del ex jugador y ex entrenador del FC Barcelona en el reportaje "El hijo del 'paleta", "Guardiola en sueños habla de fútbol. Tiene curiosidad por muchas cosas que no están en el fútbol. Pero a veces uno tiene la impresión de que las codifica de una manera especial. Que las futboliza. Si tú le cuentas una anécdota de Paco de Lucía o de Belmonte o de Cary Grant, él la archiva con devoción, pero la aplica a su juego, como si fuera un ejercicio, como si le regalas a un cocinero una raqueta de pimpón y lo primero que pensara es cómo usarla de sartén. Esa curiosidad por otros mundos, no tan habitual en los deportistas de éxito, le llega como una solución al enigma de vivir" (TRUEBA, 2010).
}

serán algunos de los motivos que estarán presentes en la novela del narrador bilbaíno. El crítico Javier Goñi (2012, p. 7) destacaría de Aquella edad inolvidable, Premio Literario Euskadi 2013, la admirable "complejidad narrativa y psicológica, a pesar de su aparente sencillez".

Respecto a las novelas que incorporan el fútbol en América Latina durante esta década, podemos comenzar destacando Dos veces junio (2002), donde el argentino Martín Kohan elabora una trama sobre los desaparecidos con el telón de fondo del Mundial de 1978. Un año después, Andrés Neuman dedicará un espacio a reinterpretar su memoria futbolística en las páginas autoficcionales de Una vez Argentina. El también argentino Sergio Olguín construirá su novela El equipo de los sueños (2004) a partir de la consideración de la primera pelota con la que jugó Maradona como un objeto mágico de valor incalculable. El chileno Hernán Rivera Letelier publicará en 2006 El Fantasista, novela situada a medio camino de la epopeya y la parodia que reactualiza el mito del héroe a través de la figura de un futbolista errante que deambula ofreciendo su espectáculo en la tierra yerma de las salitreras chilenas. Alrededor del enfrentamiento escatológico entre los equipos de los Cometierra y los Comemuertos, Rivera Letelier mantendrá viva la memoria de todos aquellos personajes que protagonizaron en Chile la "épica del salitre" (BRAVO ELIZONDO, 2007, p. 169). Continuando con otros enfoques del fútbol en la narrativa, el argentino Rodolfo Rabanal recurriría al Mundial 78 como marco de su libro El héroe sin nombre (2006). En Ecuador nos encontramos con la novela Sábados de fútbol (2007), de José Hidalgo Pallares. Por estos años también se publica una novela que aborda el tabú de la homosexualidad en el mundo del fútbol: Juego de chicos (2012), del argentino Facundo R. Soto ${ }^{5}$. Por último, apuntamos el título de cuatro novelas de autores colombianos que reflejan la consolidación de la literatura del fútbol en el país cafetero: Entre perdedores (2006), de Ethan Frank Tejeda; Pelota de trapo (2009), de Adalberto Agudelo Duque; El día en que el fútbol murió (2011), de Andrés Salcedo; y Los fantasmas de Sarrià visten de chándal (2012), de Wílmar Cabrera.

La primera década del siglo XXI también asistirá a la consolidación de formas híbridas en la literatura del fútbol. Hablamos de textos donde se combina el ensayo con la ficción, en los que las reflexiones de un escritor sobre el mundo del balompié sirven como modo de introspección personal y donde las fronteras entre

\footnotetext{
Este autor también desarrollaría la temática del fútbol dentro del mundo gay en el libro de relatos Olor a pasto recién cortado (2013). En España el tema sería abordado por Eduardo Mendicutti en algunas de las crónicas satíricas de su libro La Susi en el vestuario blanco (2003). En noviembre de 2016, en su número 57, la revista Panenka dedicaría un especial a la homosexualidad en el fútbol con el título de "Fútbol, la última barrera".
} 
géneros se antojan cada vez más difusas. En la línea de Eduardo Galeano y el inglés Nick Hornby (Fever Pitch, 1992), quizá las dos influencias más citadas por muchos de estos autores, nos enfrentamos a obras misceláneas que, en unos casos, se podrían englobar en una suerte de literatura de confesión donde los escritores dan cuenta de su relación personal con el deporte rey (SÁNCHEZ, 2007, p. 134), mientras que, en otros, el fútbol se emplea como motivo de análisis artístico, histórico o social. Un buen ejemplo de esto lo tenemos en Libre directo (2004), dietario futbolístico del catalán José María Albert de Paco en que el vínculo del autor con el RCD Espanyol le sirve de pretexto para narrar sus experiencias personales. El argentino Martín Caparrós, por su parte, entregaría una summa de Boca Juniors en el libro Boquita (2005), donde el relato de la historia del club desde sus orígenes se da la mano con una pregunta sobre el sentimiento de la hinchada. El escritor porteño, según confesaba en el prólogo, tuvo que hacer frente a los temores de hallar las razones de una pasión que en esencia carece de ellas: "Cuando me propusieron contar la pasión bostera y tratar de entenderla, me dieron tremendas ganas de intentarlo. Y mucho miedo de conseguirlo: de que la comprensión deshaga el sentimiento" (CAPARRÓS, 2012, p. 12).

Llegamos así a la figura del mexicano Juan Villoro, uno de los referentes de la literatura del fútbol en la actualidad. Entre su obra de ficción podemos mencionar los cuentos "El extremo fantasma" (1995), dentro de la primera antología de Valdano, y "El silbido" (Los culpables, 2007); además de los relatos "Los sucesores" y "Yo soy Fontanarrosa", piezas cargadas de ironía que rinden homenaje a algunos de sus ídolos literarios y futbolísticos pertenecientes al volumen Apocalipsis (todo incluido) (2014). En cuanto a sus libros de ensayo y crónica, han sido fundamentales en el desarrollo del fútbol como tema literario. Periodista y crítico a la par que novelista, hincha que le va a un equipo perdedor como Necaxa, Villoro ha recogido su producción futbolera en los libros Los once de la tribu (1995), Dios es redondo (2006) y Balón dividido (2014). Si en el primero de ellos sus reportajes sobre fútbol conviven todavía con otras temáticas, los dos últimos estarán dedicados por entero al balompié. Su análisis de las relaciones entre fútbol y literatura, así como su acercamiento a motivos que van del juego en la infancia a la caída del héroe, lo convertirán en uno de los autores más citados de la literatura balompédica. Por su parte, los correos que Villoro y Caparrós intercambiaron con motivo del Mundial de Sudáfrica en 2010, publicados primero en las revistas Soho y Letras Libres, serían recogidos en Ida y vuelta, una correspondencia sobre fútbol (2012). En definitiva, resulta posible afirmar que los ensayos del escritor mexicano dieron paso a una mayor complejidad del pensamiento futbolero que también encontramos, por ejemplo, en el volumen Fútbol. La vida en domingo (2006), del sociólogo y escritor argentino Pablo Nacach. Al mismo tiempo, continúan desarrollándose en la literatura en español las formas híbridas que toman el fútbol como punto de partida, según se observa por ejemplo en los libros del madrileño Montero Glez (Diario de un hincha, 2006, y El gol más lindo del mundo y otras piezas futboleras, 2014) o el argentino Walter Vargas (Cambios de frente, 2008, y Equipos cortos, 2013).

Una de las muestras más destacadas de la adopción del fútbol como tema será la colección "Hooligans Ilustrados", editada desde 2012 por la editorial española Libros del K.O. y en la que una serie de escritores y periodistas cuentan en libros de pequeño formato la relación con su equipo de fútbol. En todos ellos encontramos algunos de los motivos en los que insiste la actual literatura balompédica, como pueden ser el gusto por el fútbol de antaño o la reivindicación del sentimiento de pertenencia ligado a la infancia. Entre el ensayo autobiográfico y el relato de forofos, forma híbrida que da cabida a narradores de todo tipo, las líneas argumentales de la colección "Hooligans Ilustrados" quedan resumidas a la perfección en las frases con que se presenta la serie en la web de la propia editorial: "El fútbol hecho literatura. El alimento espiritual de fajadores y tuercebotas. La crónica sentimental de un escritor a través de los colores de su equipo de fútbol. Algo de épica y mucho barro" ${ }^{6}$. Hasta el día de hoy se han publicado un total de quince títulos a cargo de los siguientes autores: Enric González, Marcos Abal, Julio Ruiz, Manuel Jabois, Antonio Luque, Ignacio Martínez de Pisón, Ander Izagirre, Antonio Agredano, Enrique Ballester, Eduardo Rodrigálvarez, José Lobo, Javier Triana, Alfonso Armada, Quique Peinado y Luis María Valero.

La iniciativa de esta pequeña editorial española encontraría su equivalente al otro lado del Atlántico en la colección "Amor a la camiseta", impulsada en su sello Lolita Editores por el escritor y periodista chileno Francisco Mouat, autor de libros de anécdotas futboleras (Cosas del fútbol, 1989, y Nuevas cosas del fútbol, 2002) y uno de los mejores conocedores de la literatura balompédica en América Latina. Los textos de "Amor a la camiseta" responderán al mismo propósito y estética que los de "Hooligans Ilustrados", en ambos encontramos esa defensa del fútbol como reducto identitario inalienable junto a la reivindicación de su apasionado valor simbólico. Tal y como afirmaba su editor en una entrevista, estos libros no solo buscan un escritor que sea hincha de un "equipo chileno y escriba de él, sino que sea capaz de desplegar

\footnotetext{
$6<$ http://www.librosdelko.com/collections/hooligans-ilustrados $>$. Acceso en 12 feb. 2017.
} 
un lenguaje de calidad, que trascienda para cualquier buen lector. No queremos atiborrar con información, sino que buscamos sensibilidad" (ROMERO, 2015). El propio Francisco Mouat sería autor de uno de los libros de esta colección, en la que también han participado Esteban Abarzúa, Patricio Hidalgo, Carlos Vergara, Diego Zúñiga, Cristóbal Joannon, Agustín Squella y Antonio Martínez.

\section{La persistencia del juego}

Durante los últimos cinco años observamos cómo se acentúa en la narrativa en español la tendencia de emplear el fútbol como motivo que permite acceder a esa memoria intransferible expresada en el juego. Por lo que se refiere a la novela, el escritor que mejor sabrá plasmar esta idea será el español Miguel Ángel Ortiz, nacido en 1982 en Ciudad del Cabo de padre burgalés y madre uruguaya. En su primera novela, Fuera de juego (2013), recreará las vacaciones en un pueblo castellano de unos niños para los cuales el fútbol forma parte esencial de su formación. Después de esta incursión en la infancia, en su segundo libro, La inmensa minoría (2014), Ortiz empleará la potencialidad simbólica del fútbol para profundizar en la educación sentimental de un grupo de adolescentes en un barrio del extrarradio de Barcelona durante el transcurso del Mundial de Sudáfrica. Deudor de la tradición de la novela social y de autores como Rafael Sánchez Ferlosio, Juan Goytisolo, Juan Marsé o Francisco Candel; Miguel Ángel Ortiz se vale del balompié para acceder a la mentalidad de unos chicos excluidos en los que el deporte representa una de sus pocas válvulas de escape: "El autor hace un retrato de gentes pobres, sencillas, de antihéroes de hoy. En la atmósfera que acoge la pintura no gusta ni de la crudeza ni de la exasperación" (SANZ VILLANUEVA, 2015, p. 113). Más allá de sus dos novelas, este escritor continúa profundizando en las relaciones entre fútbol y literatura en una serie de artículos publicados en la revista Panenka y también en su blog "A ras de hierba" ". Su evocación del fútbol callejero, de los partidos que se arman en cualquier descampado con apenas dos piedras, de la desolación que acompaña a los balones deshinchados y a los primeros amores; convertirán la obra de Ortiz en uno de los mejores y más actuales ejemplos de mitificación del juego en la literatura en lengua castellana.

Durante este periodo otras novelas de autores españoles ahondarán en la tematización del fútbol. El zamorano David Refoyo imaginará en El día después (2014) la figura de un analista capaz de predecir con prodigiosa exactitud los resultados del campeonato de Liga. El bilbaíno José María Isasi, quien ya en 1998 había escrito unas sorprendentes Variaciones Julen

\footnotetext{
<https://arasdehierba.wordpress.com/>. Acceso en 4 mar. 2017.
}

Guerrero, regresaría a la cartografía sentimental del fútbol en Euskadi con El hijo del hincha (2015), novela en la que reniega de la mercantilización del fútbol moderno. En El hombre que mató a Messi (2015), la catalana Emma Riverola se meterá en la mente de un atormentado defensa que acaba por accidente con la vida del mejor futbolista del mundo: "Veinte años volviendo a ese silencio de duelo que se apoderó del Camp Nou aquella tarde" (RIVEROLA, 2015, p. 9). Juanjo Díaz Polo evocará en Jóvenes promeses (2016) la gesta del equipo español de fútbol que conquistó en 1920 la medalla de plata en los Juegos Olímpicos de Amberes dando origen al tópico de "La furia". A través de la voz de la hija de un cronista deportivo, Díaz nos transporta a aquellos tiempos mediante la ficcionalización de personajes reales como el entrenador Paco Bru o los jugadores Ricardo Zamora y José María Belauste. Este mismo año se publica la novela Ascenso y caída de Humberto da Silva (2016), donde el salmantino José Luis Muñoz ahonda en el mito heroico a través del periplo de un futbolista brasileño surgido de las favelas de Salvador de Bahia. En cuanto a la literatura latinoamericana, podemos destacar la novela La luz oscura (2013), en la que el chileno Nicolás Vidal rememora la represión y las torturas en el Estadio Nacional durante la dictadura de Pinochet a partir del vínculo que un padre y un hijo entablan en torno a su equipo. El también chileno Carlos Labbé publica un año después La parvá, novela ambientada en el Mundial de 1962 y estructurada a partir de las hipnóticas narraciones de un comentarista deportivo. Por último, el periodista y escritor argentino Daniel Frescó narrará en Enfermo de fútbol (2015) la vida de un fanático anacoreta contemporáneo que decide renunciar a todo para pasar el resto de su vida contemplando partidos por televisión ${ }^{8}$.

Así como en la novela la voz más relevante será la del español Miguel Ángel Ortiz, entre los autores actuales de cuentos sobre fútbol destacará por encima de todos el argentino Hernán Casciari. Nacido en 1971 en la ciudad de Mercedes pero residente durante muchos años en Barcelona, la obra de este escritor y periodista se halla dispersa en multitud de libros, revistas literarias y medios digitales en los que refleja su mirada transatlántica. Impulsor de nuevos géneros como la llamada

\footnotetext{
8 Dejamos aquí también, sin ánimo de exhaustividad, el nombre de algunas novelas brasileñas que han aportado nuevos puntos de vista a la literatura del fútbol. Destaca por encima de todas $O$ drible (2013), en la que su autor, Sérgio Rodrigues, parte de la mitificación de una jugada de Pelé en el Mundial de 1970 para elaborar una fantasía en torno a un futbolista mágico y a un personaje inspirado en el periodista Mário Filho. También podemos mencionar otras novelas como $O$ segundo tempo (2006), de Michel Laub; O Paraíso é bem bacana (2006), de André Sant'Anna; O último minuto (2013), de Marcelo Backes; y Tijucamérica. Uma chanchada fantasmagórica (2015), de José Trajano. En cuanto a la presencia del fútbol en el relato breve brasileño destacan nombres como Aldyr García Schlee, Ronaldo Correia de Brito, Fernando Bonassi, Cristóvão Tezza o Adriana Lisboa.
} 
blogonovela, nos hallamos frente a un autor en búsqueda de un permanente contacto con sus lectores que no duda en sortear sus libros dependiendo del resultado de un partido de la selección argentina y que, además de ofrecer de forma gratuita la lectura de sus cuentos en internet, difunde su obra en giras y representaciones teatrales con gran asistencia de público. Hincha entregado y sufriente de Racing Club de Avellaneda, el fútbol será para Casciari obsesión, vínculo y motivo de indagación estética. Si bien podemos encontrar algunas referencias al balompié en novelas autobiográficas como El pibe que arruinaba las fotos (2009), la mayoría de su obra futbolística se expresará a través de la narrativa breve. Algunos de sus mejores relatos serán publicados por primera vez en la Revista Orsai, proyecto editorial innovador sin publicidad y con un cuidado diseño gráfico que atrajo entre 2011 y 2014 a importantes autores hispanoamericanos. Casciari continuaría publicando numerosas piezas sobre fútbol en su blog "Orsai", mientras que en marzo de 2017 la revista volvería a la imprenta. En 2012 vería la luz en el número seis de la publicación el cuento "El tiempo del hombre perro" que, ya con su definitivo título de "Messi es un perro", habría de convertirse en un fenómeno viral de internet con millones de visitas en vídeos con la narración de un relato centrado en la ficcionalización y el análisis del componente lúdico presente en la forma de juego de Lionel Messi. Del mismo modo, el cuento "10.6 segundos" (2013) recreará con minuciosidad borgeana el célebre "Gol del siglo" de Maradona contra los ingleses. En 2015 el escritor argentino incluiría algunos de sus mejores relatos sobre fútbol en el libro Messi es un perro $y$ otros cuentos, publicado en su propio sello. Heredero del sentido de la oralidad y la desbordante ironía que presidía los cuentos futboleros de Fontanarrosa y Soriano, Casciari encarnará la vigencia de los mitos de la literatura del fútbol y su difusión a través de los nuevos medios.

Entre otros autores que trabajarán el relato breve sobre fútbol durante estos años podemos nombrar al colombiano Diego Mauricio Cortés Zabala, quien en 2013 ganaría el XI Concurso Nacional de Novela y Cuento de su país con el volumen Tiro libre. En Argentina, Fernando Kleiman publicará Locura de mi corazón. Cuentos de fútbol, amor y muerte (2012), mientras que Víctor Belchior sacará a la luz un libro de relatos sobre Boca Juniors con el título de Historias de Boca en Boca (2014). Eduardo J. Quintana proseguirá la tradición del relato futbolístico argentino en De fútbol y barrio (2013) y Con la ilusión en ascenso (2015). Dentro de la literatura española, podemos destacar el cuento de Jorge Gamero "La alineación" (Las tres caras de la moneda, 2013) y el de Juan Bautista Durán "Convivir con el genio" (2014),

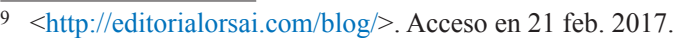

incluido en el libro del mismo nombre. En 2016 saldrá a la luz la colección de cuentos futbolísticos del cordobés Pablo Santiago Chiquero titulada Once goles y la vida mientras, en la que su autor recurre a algunos de los goles más célebres de la historia como motivo desde el que abordar la vida de personajes anónimos. En este libro encontramos goles como los dos tantos de Maradona a Inglaterra en 1986, el de Iniesta en la final del Mundial, el último de Juan Señor en el 12-1 de España a Malta, el lanzamiento de falta de Koeman que dio al Barcelona su primera Copa de Europa, junto a otros goles y episodios protagonizados por futbolistas reales como Zidane, Cantona, Guardiola, Gerrard o Butragueño.

Al mismo tiempo que se sigue trabajando el tema del fútbol en la literatura de ficción, comprobamos cómo se desarrollan las formas híbridas, principalmente en España. Uno de los ejemplos más relevantes será el del gallego Juan Tallón en su Manual de fútbol. Un libro fuera de juego (2014). Conformado por breves ensayos en los que describe diferentes aspectos del juego, Tallón concibe sus textos entre la ficción, el apunte y la crónica. En $L a$ balada del Bar Torino (2014) Rafa Lahuerta compone unas memorias apasionadas alrededor del Valencia CF por las que asoman personajes como Max Aub, Mario Alberto Kempes o Paco Roig. Por su parte, el cántabro Fran Díez trabajará el relato breve en La dictadura del fútbol (2014), mientras que en El balón quema, la grada arde (2015) se acercará al ensayo y el libro de viajes. El escritor asturiano Fernando Menéndez redactará un diario futbolístico en torno al Real Oviedo en Víctimas de la espera (2015), donde emplea poesía y prosa para dar cuenta de la supervivencia del equipo en tercera división. Los chilenos Jerónimo Parada y Andrés Santa María nos dejarán un peculiar ejemplo de mitologización de jugadores reales de fútbol en los retratos de Pelota sudaca (2015), libro en el que funden y renuevan los motivos de los héroes clásicos con los de la mitología indígena. Sobre este libro dirán sus autores en el prólogo que es resultado de "dibujar una y otra vez los misteriosos recovecos de las vidas de los genios sudamericanos, esos caminos que se vuelven a abrir incrustándose en el pasado para parir nuevos dioses" (PARADA y SANTA MARÍA, 2015, p. 10). El catalán Sergi Pàmies trabajará el ensayo sentimental sobre el Barça en la senda de Manuel Vázquez Montalbán en sus Confesiones de un culé defectuoso (2016). Por último, el ex futbolista y filólogo onubense Miguel Pardeza sacará a la luz el libro autobiográfico Torneo (2016), donde, tomando elementos autoficcionales, recuerda su llegada a la cantera del Real Madrid y acerca del cual su autor aseguraba en una entrevista que "encaja en la literatura de formación, o mejor dicho de iniciación, aunque no quiero olvidarme lo que el libro tiene, por supuesto, de autoconocimiento" (RODRÍGUEZ, 2016). Este libro se 
alzaría en febrero de 2017 con el premio de la revista Panenka al mejor libro sobre fútbol publicado en 2016.

\section{Conclusiones}

El recuento de todas estas obras muestra una consolidación del fútbol como tema dentro de la narrativa en lengua española en la actualidad. El largo camino iniciado a comienzos del siglo XX, consolidado a partir de los años setenta, nos lleva a apreciar una legitimación cada vez mayor del fútbol como tema literario. La memoria sentimental de los escritores e hinchas, la orgullosa pasión por unos colores, la recurrencia de la nostalgia, en definitiva, el fútbol como metáfora, se traduce en una diversificación de las formas literarias al amparo de la aparición de otros soportes. El surgimiento de nuevas editoriales sin reparos a la hora de añadir el fútbol a su catálogo convivirá con la difusión de la literatura balompédica en redes sociales y blogs, algunos de ellos a cargo de los propios escritores. A tenor de lo visto, todo parece indicar que fútbol y literatura afianzan durante estos años una relación con perspectivas de futuro. No en vano, ambas actividades, cada una con las herramientas a su alcance, se alimentan de una búsqueda formal y estética capaz de ofrecer nuevas formas de conocimiento: "La literatura revela las sutiles y variadas implicaciones que encierran los acontecimientos futbolísticos [...] nos invita a proyectarlos sobre otros acontecimientos de su misma naturaleza" (NÚÑEZ RAMOS, 2015, p.185186). En ocasiones despreciado por los intelectuales, en muchas otras ensalzado, resulta innegable afirmar que el fútbol, como uno de los principales fenómenos de masas de nuestro tiempo, se ha incorporado de forma cada vez más acusada a la narrativa en lengua española durante las primeras décadas del siglo XXI. Los escritores toman la palabra para aportar una mirada compleja y reactualizar aquellos símbolos ligados al universo futbolístico. Cuentos, novelas y formas híbridas ayudan a resignificar el juego y fijarlo en la memoria. Los narradores, en definitiva, continúan soñando con inscribir los goles en el tiempo.

\section{Referencias}

AÍNSA, Fernando. Narrativa hispanoamericana del siglo $X X$ : del espacio vivido al espacio del texto. Zaragoza: Prensas Universitarias de Zaragoza, 2003.

BONILLA, Juan. Blaugrana. En: La plaza del mundo. Valladolid: Universidad de Valladolid, 2008. p. 107-119.

BRAVO ELIZONDO, Pedro. Reseña de El Fantasista. Revista de Ciencias Sociales, n. 19, p. 167-170, 2007.

CAPARRÓS, Martín. Boquita. Buenos Aires: Booket, 2012.
DÍAZ ZULUAGA, Luis Alejandro. Literatura y fútbol: otros horizontes de la literatura en España e Hispanoamérica. 406 hojas. Tesis (Doctorado) - Universitat Autònoma de Barcelona, 2014.

GOÑI, Javier. La mano de Dios. El País, 2 jun. 2012, p. 7.

HUIZINGA, Johan. Homo ludens. Madrid: Alianza, 2008.

NACACH, Pablo. Fútbol. La vida en domingo. Madrid: Lengua de Trapo, 2006.

NÚÑEZ RAMOS, Rafael. ¡Maracaná! Fútbol y literatura en una palabra. Castilla. Estudios de Literatura, v. 6, p. 159-188, 2015

PARADA, Jerónimo; SANTA MARÍA, Andrés. Pelota sudaca. Santiago de Chile: La Pollera Ediciones, 2015.

RIVEROLA, Emma. El hombre que mató a Messi. Barcelona: Edhasa, 2015.

RODRÍGUEZ, Jorge. Un país donde se considera que leer es una rareza padece una enfermedad social grave. Entrevista con Miguel Pardeza. Letras Libres, ago. 2016. Disponible en: <http://www.letraslibres.com/espana-mexico/cultura/unpais-donde-se-considera-que-leer-es-una-rareza-padece-unaenfermedad-social-grave>. Acceso en: 18 ene. 2017.

RODRÍGUEZ, Oriol. No acepto el aburrimiento. Entrevista a David Trueba. Panenka. El fútbol que se lee, n. 40, p.92-97, abr. 2015.

ROMERO, Pablo. Lolita, un rincón chileno dedicado a libros de fútbol durante la Copa. El Tiempo, 19 jun. 2015. Disponible en: <http://www.eltiempo.com/deportes/futbol/coleccion-delibros-de-franciscomouat/15972396>. Acceso en: 15 ene. 2017.

SACHERI, Eduardo. La vida que pensamos. Cuentos de fútbol. Madrid: Alfaguara, 2014.

SÁNCHEZ ZAPATERO, Javier. La cultura de la memoria. Pliegos de Yuste, n. 11-12, p. 25-30, 2010.

SÁNCHEZ, Yvette. La literatura del fútbol, ¿metida en camisa de once varas? Iberoamericana, v. 7, n. 27, p. 131-142, 2007.

SÁNCHEZ, Yvette. Derrotas sublimes: la literatura y el deporte rey. Hispanorama, n. 128, p.9-14, 2010. Disponible en: <http:// www.enriquevilamatas.com/escritores/escrsanchezyv3.html>. Acceso en: 14 feb. 2017.

SANZ VILLANUEVA, Santos. Antihéroes de hoy. Cuadernos hispanoamericanos, n. 776, p. 111-114, feb. 2015.

TALLÓN, Juan. Manual de fútbol. Un libro fuera de juego. Barcelona: Edhasa, 2014.

TRUEBA, David. El hijo del paleta. El País, 22 ago. 2010. Disponible en: <http://elpais.com/diario/2010/08/22/eps/ 1282458417_850215.html>. Acceso en: 8 nov. 2016.

VILLORO, Juan. Dios es redondo. Barcelona: Anagrama, 2006.

VILLORO, Juan. Balón dividido. México: Planeta, 2014.

Recebido: 15 de março de 2017

Aprovado: 09 de setembro de 2017

Contato:

David García Cames < garciacames@gmail.com>

ORCID: https://orcid.org/0000-0003-4385-2900 